\title{
Automatic Extraction of Rarely Explored Materials and Methods Sections from Research Journals using Machine Learning Techniques
}

\author{
Kavitha Jayaram ${ }^{1}$, Prakash $\mathrm{G}^{2}$ \\ Department of Computer Science and Engineering \\ Amrita School of Engineering \\ Amrita Vishwa Vidyapeetham, Bengaluru, India
}

\author{
Jayaram $\mathrm{V}^{3}$ \\ Solid States and Structural Chemistry Unit \\ Indian Institute of Science, IISc \\ Bengaluru, India
}

\begin{abstract}
The scientific community is expanding by leaps and bounds every day owing to pioneering and path breaking scientific literature published in journals around the globe. Viewing as well as retrieving this data is a challenging task in today's fast paced world. The essence and importance of scientific research papers for the expert lies in their experimental and theoretical results along with the sanctioned research projects from the organizations. Since scant work has been done in this direction, the alternative option is to explore text mining by machine learning techniques. Myriad journals are available on material research which throws light on a gamut of materials, synthesis methods, and characterization methods used to study properties of the materials. Application of materials has many diversified areas, hence selected papers from "Journal of Material Science" where "Materials and Methods" sections contains names of the method, characterization techniques (instrumental methods), algorithms, images, etc. used in research work. The "Acknowledgment" section conveys information about authors' proximity, collaborations with organizations that are again not explored for the citation network. In the present articulated work, our attempt is to derive a means to automatically extract methods or terminologies used in characterization techniques, author, organization data from "Materials and Methods" and "Acknowledgment" sections, using machine learning techniques. Another goal of this research is to provide a data set for characterization terms, classification and an extended version of the existing citation network for material research. The complete dataset will help new researchers to select research work, find new domains and techniques to solve advanced scientific research problems.
\end{abstract}

Keywords-Data-mining; rule-based; machine-learning; term extraction; classification; materials and methods; acknowledgment

\section{INTRODUCTION}

Citation networks have been well analyzed both syntactically as well as structurally but there is a strong need for semantic analysis for these networks. Citation analysis as the most significant area of bibliometric that has been studied using the Page Ranking algorithm for a long time and there has been a great deal of research work in this direction [1]. Citation sentiment analysis is used to determine sentiment polarity of clinical trial papers using n-gram and sentiment lexicon features on annotated corpus [2]. A summary of a corpus of research papers, domain-independent structural relations between abstracts and domain of scholarly medical articles, state-of-the-art deep learning baseline was constructed and has been reported [3]. Given a particular paper of interest, CiteSeer can display the context of how the paper is cited or indexed in subsequent publications with a summary of the paper in electronic format [4]. The semantic analysis of paper abstracts is a good start for annotating papers using Natural Language Processing (NLP) with semantic metadata and for increasing the general representation and visualization of the key concepts within a given domain [5]. Here they discuss and analyze the text mining techniques and their applications in diverse fields [6]. The collaboration of productive authors based on the topics, collaborative effort, highly cited articles, etc. would identify the relationship between two specific nodes that can reveal scholarly communication patterns (i.e., collaboration or knowledge diffusion, copyright transfer) with finer granularity [7]. The author proposes a mathematical model that matches empirical acknowledgment data closely for citation patterns which give cognitive interdependence among disciplines [8]. A function of appreciation using the acknowledgment section within academia of the instrumental and normative significance has been presented [9]. A content-based image retrieval system that extracts, image features from journal papers using a supervised learning algorithm has been explained in [10]. An overview of the principles and methods of automatic term recognition of significant elements have been presented [11]. From conference proceedings and journal papers information extracted like dataset, content, and basis of extraction summarized in Appendix I. Scientometrics researchers use structural/syntactic information from a bibliographic network for qualitative analysis of the same network [12]. Some common aspects like the dataset used, methods, the most focused problem in a particular field, frequently used algorithms, hot areas such as analysis of research trends have been extracted [13]. Fig. 1 represents the existing citation network focuses on citation count and co-authorship hence it mainly contains four nodes namely Venue, Paper, Term, and Author/co-authors [12].

The "Abstract" section contains the best ratio of keywords per total of words, which contains research, material, methods used and challenges faced, but many times they do not include methods. Hence, the next most important findings of the research are expressed in "Materials and Methods" section such as experimental techniques, instrumental methods, algorithm, figures, etc. Acknowledgments section is used to express 
appreciation between researchers, direct or indirect collaborators, and the contribution of external people or organizations. These aspects of the citation network are important and are needed to be explored to improve author proximity, affiliations, and funding organizations that contribute to academic or industrial research. It is found that the automatic identification of methods and acknowledgment influences the citation network. The modified citation network where few other nodes like "organization" have been included to study the author collaboration, method and dataset nodes from Materials and Methods section to analyze compounds or materials is shown in Fig. 2. It is clear that extracting the above mentioned important information from the "Journal of Material Science" and incorporating it into the existing citation network give us new ways to look at the authors' communities, collaborators from organizations and institutions in material research. This paper describes the automatic extraction of materials, characterization techniques, instrument-related terminologies, acknowledged by authors (organization) using Machine Learning (ML) techniques.

This paper is organized as follows: Section 2 covers the implementation of the algorithm, tools, framework, and work executed in the present research. Section 3 explains the experiments, results, and discussion. Section 4 summarizes the present work and future research which can be laid upon the work. In the last Section, we acknowledge the research collaborators. Appendix I include a list of reference papers where the information is extracted from the present published research papers. Appendix II gives lists of sample research papers from the research journals with title, materials, and characterization techniques. Appendix III gives a list of characterization methods used to investigate the results presented in the materials and methods section of the journal publications.

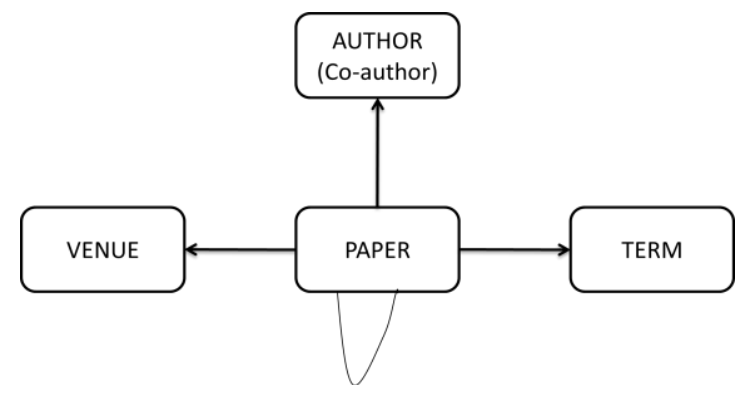

Fig. 1. Current Citation Network Analysis.

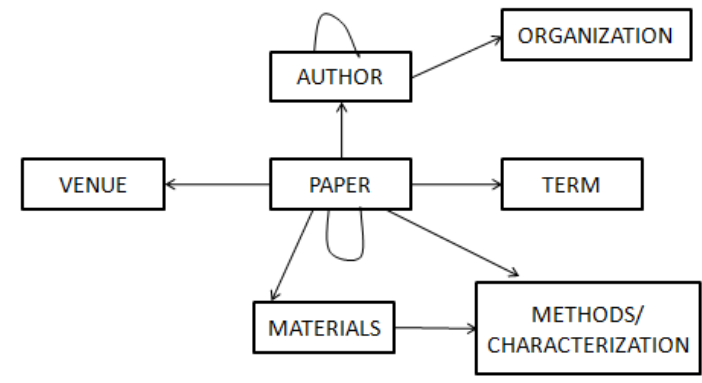

Fig. 2. Modified Citation Network for Materials and Methods from Scientific Journals.

\section{IMPLEMENTATION}

The building of a heterogeneous network includes different types of entities and incorporating into the currently existing citation network. The main work comprises finding out the entity mentioned (characterization techniques and organization names) from the research work. The implementation details mainly focuses on the "Materials and Methods" section which includes materials, methods, figures, micrographs, images, and material characterization obtained from different instrumental methods. To analyze "Material and Methods" section, it is required to convert the extracted information into a format compatible with usual heterogeneous citation networks. New node types such as "Algorithm, technique, method", "characterization, measurements, instruments", "Images or figures" and "Organization funding" form the key semantic components of the research work. To the best of our knowledge, no such work has been done with "Materials and Methods" and "Acknowledgment" sections from material research journals using machine learning techniques.

The statistical approach generally uses information such as term frequency, term-document frequency, inverse termdocument frequency, etc. for extracting the important entities and mentioned phrases. Named entity recognition (NER) is also a problem that attempts to find out mention, author, organization, place, etc. Although their extraction is very good, it is limited to particular classes and does not have any model to mention terminologies and acronym. Although a lot of work has been done on domain-specific term extraction and named entity extraction for particular classes, the method keywords extraction has not been explored. Both rule-based and ML approaches to find methods were mentioned in a scientific research document to extract important techniques and methods used in biomedical research [14].

Scientific documents are mostly available in PDF format, which is semi-structured and not tagged, unlike HTML, also 'text' in them is usually arranged in multiple rows and columns. Many tools are available to extract text from PDFs, but when documents come with multiple rows and columns like tables, figures, etc., text extraction tool is not good enough ${ }^{11}$. A rulebased approach that is leveraged to extract the required sections is proposed using regular expressions and was reported in [15]. Single-word does not represent an entity, but a sequence of words does, support vector machine (SVM), linguistic-based techniques for entity extraction generally uses part-of-speech (POS) tagging and the dependencies of the words upon each other [16]. The ML algorithms used are Naïve Bayes' classifier, decision tree, and maximum entropy classifier. Extraction of a vast number of terminologies and acronyms from the "Materials and Methods" section is not an easy task. New methods and techniques are being used and named with new emerging problems. Using PDFBox and TET tools, the extraction of spatial co-ordinates and formatting information of text has been completed. In the present research work, automatic extraction of entities like text, single nouns and compound nouns has been carried our using a machine learning approach instead of linguistic methods.

\footnotetext{
${ }^{1}$ http://www.pdflib.com/products/tet/
} 
Primarily the 'text' has been extracted using PDFBox text extraction tool, and then the co-ordinates of words and lines in the documents were calculated. This helps in calculating the coordinates of the line where the section name is extracted using regular expression, starting from one section to the next section, using a regular expression. Further "Materials and Methods" and "Acknowledgment" sections were also extracted individually from PDF into a text format using a section extraction algorithm as presented in Fig. 3. After extracting the required sections the terminologies like names of the materials, characterization techniques, methods, authors, organization, etc. are extracted from the text file. Terminology and acronym for materials and characterization techniques from the sample journals are listed in Appendix II.

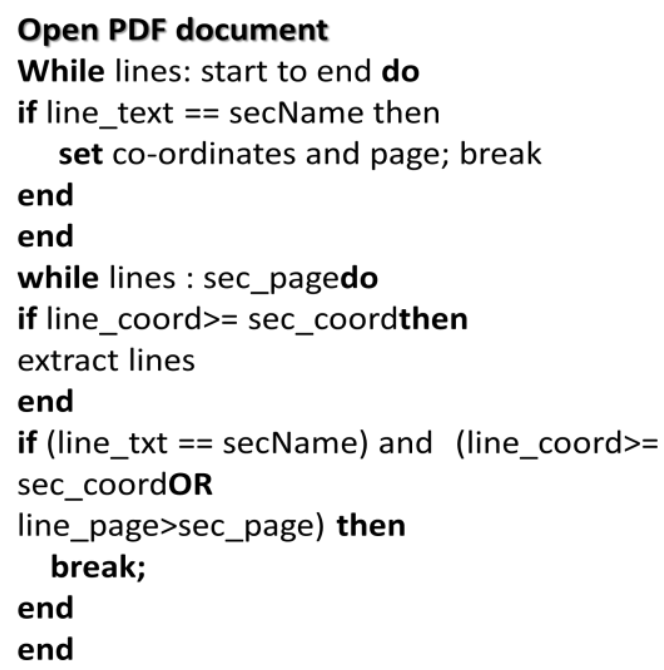

Fig. 3. Section Extraction Algorithm [12].

The following two categories were considered for extracting acronym:

Category 1: Methods ending with keywords (such as analysis or scope) eg.: Energy Dispersive X-Ray Analysis/spectroscopy (EDX or EDS).

Category 2: Methods do not have any keywords. eg.: X-ray Diffraction (XRD).

New dataset was created by selecting data from nearly 800 research papers, where it contains methods and characterization techniques. The method mentions in the dataset representing the characterization techniques (or Instrumental methods), algorithm, theory, model are considered in the form of nouns. In category 1 , methods are extracted using regular expressions to create the training dataset. Hence POS (Part of Speech) was used for tagging to extract names of all methods, though they fall into any of these two categories. When data falls into category 2 , supervised machine learning algorithms have been used, for which a good quantity of training dataset is required. All the relevant characterization techniques and abbreviations are listed in Appendix III. Different classification algorithms were run over datasets and evaluated by precision, recall, and F1-score techniques using the following formulas [17]:

$$
\begin{aligned}
& \begin{array}{l}
\text { precison } \\
=
\end{array} \\
& \text { recelevant documents }\} \cap\{\text { retrieved documents }\} \mid \\
& \mid\{\text { retrieved documents }\} \mid \\
& =\frac{\mid\{\text { relevant documents }\} \cap\{\text { retrieved documents }\} \mid}{\mid\{\text { relevant documents }\} \mid} \\
& \text { Precision }=\frac{t_{p}}{t_{p}+f_{p}}, \quad \text { Recall }=\frac{t_{p}}{t_{p}+f_{n}} \\
& \text { F }=2 * \frac{\text { Precision } * \text { Recall }}{\text { Precision }+ \text { Recall }} \\
& \text { Balance accuracy }=\frac{\mathrm{TPR}+\mathrm{TNR}}{2} \\
& \text { TPR }=\frac{\mathrm{tp}}{\mathrm{tp}+\mathrm{fn}} \text { and TNR }=\frac{\mathrm{tp}}{\mathrm{tp}+\mathrm{fp}}
\end{aligned}
$$

Whereas for classification, the following terms are used to compare the results of the classifier: the term $t_{p}$ is true positives, $t_{n}$ is true negatives, $f_{p}$ is false positives, $f_{n}$ is false negative, further, TPR is term positive rate and TNR is term negative rate. Precision is the fraction of relevant instances among the retrieved instances, while recall fraction of the total amount of relevant instances that were actually retrieved. F1score is the harmonic mean of precision and recall. TPR and TNR are statistical classification for a confusion matrix or error matrix. The terms positive and negative refer to the classifier's prediction (expectation) and true and false terms refer to the prediction corresponds to the external judgment (observation) [18].

\section{RESULTS AND EXPERIMENTS}

Present experiments were performed on system configuration having 128 GB RAM by using Python 3.0 with nltk and also Java as the programming language.

Data pre-processing was performed before collecting training data, such as removing all stop words, commas, semicolons, newlines (which were unnecessarily present because the data was extracted from pdfs). The papers were downloaded from an official website of "Journal of Material Science (JMS)". The text contained in the documents was extracted using PDFBox tool. Even this tool is not found to be very promising in retaining the structure of the extracted text. Since the data is in PDF format, it is a difficult task to use all the information available in the research documents. Therefore, data pre-processing becomes an important and time consuming task. Spatial coordinates of the words to form the lines and to keep the lines in correct order are also an important task. After working on many methods, good results were achieved by a supervised classification method approach. Summary of noun phrases from journal papers and Wikipedia entries term sequence are listed in Appendix III.

Both "Materials and Methods" and "Acknowledgment" sections are derived using the regular expression based rules. Previous work on section extractions shows that regular expressions achieve 100\% precision and 67\% recall for extracting Acknowledgment section [19]. The proposed analysis shows that same approach works for the Materials and 
Methods section too. Hence regular expressions and spatial coordinates are used to extract both sections of the research paper. NLP technique is used to extract sentences having the materials name, algorithm methods or characterization, measurement, etc. words. StandfordCoreNLP tool is used for named entity recognition [20]. Using these entities a list of the most widely used methods or simulation work done in material research are listed in Appendix III. Named Entity Recognition (NER) is used to extract sentences from different papers to find out methods, characterization, algorithms, people / authors, and organizations.

Noun phrases available in the research paper are searched from the Wikipedia entries. The summaries of the term sequences were collected while rejecting the sequences that were not available in Wikipedia entry. Along with these entries documents were clustered into five classes using Linear Discriminant Analysis (LDA), the list of methods predicted in a paper (w.r.t. materials used for research) is shown in Fig. 4(a). Using nearest neighbor and supervised methods the corresponding classes were assigned to dominant topics. With the important extracted information, the Citation Network is extended to provide dataset related to collaborators and authors due to newly introduced nodes in the network. The results obtained also include a new dataset for characterization techniques from the research paper.

The main goal is to extract the characterization or methods from the research papers. Initially, about 100 term sequences from various research papers were manually tagged as methods (characterization methods). These 100 terms were extracted from research papers and Wikipedia entries terms using rulebased regular expressions techniques based on machine learning and NLP methodologies. Subsequently all the relevant stop words, commas, semicolons, newlines (which are unnecessarily present because of the data extracted from pdf's) were removed from the extracted text. Although many of the problems that arose owing to the pdf's extraction were addressed, few problems remain unsolved. Few problems like, unnecessary spacing between few words, some non-ASCII characters, and distortion of table data are attributed as the primary reasons for messing up in text data. These mistakes could have a detrimental effect on the output. The features extracted from the text are automatically run by the program where the positive and negative class term sequences are encountered.

The process of searching term sequences in the whole document set for creating the training data manually while considering positive and negative term sequences with a ratio of 5:3, but the ratio obtained was about 1:9. This is the class imbalance problem that occurred due to the specificity of the positive term sequences and all the general noun phrases coming into negative class. This class imbalance problem was resolved by applying entity clustering for sampling negative class instances, where the ratio was about 6:4. Fig. 4(a) shows the list of materials classified as carbon, graphite, silica, electronic, and high-temperature materials (HTC) along with a sub-classified list of few compounds selected from the Journals. Fig. 4(b) shows the list of characterization techniques from different instrumental methods like XRD, SEM, TEM, etc. including few simulation and ML done on the selected materials. Summary of the characterization methods used to analyze the material selected from the "Materials and Methods" section of the Journal are listed in Table I. All these classifications are considered while solving problems using machine learning techniques.

The materials and characterization techniques extracted from the Journal gives the following conclusion. The bar graph in Fig. 5(a) shows that $\mathrm{TiO}_{2}$, Graphene materials appear in more research papers compared to other compounds. However, in Fig. 5(b) shows XRD and SEM instruments used extensively as characterization techniques for material analysis. Our results from the machine learning techniques reveals the statistics of materials not explored by the researchers and the type of methods not used for characterization of materials including simulation work. The present research work provides a dataset for materials and methods for selecting particular area of research by the scientific community.

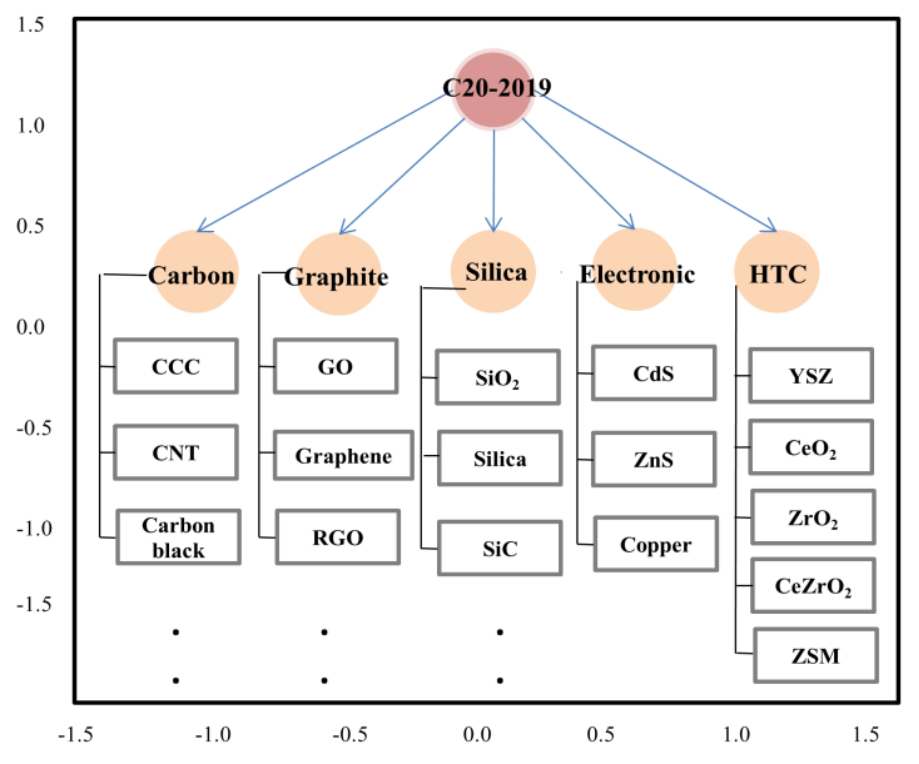

(a)

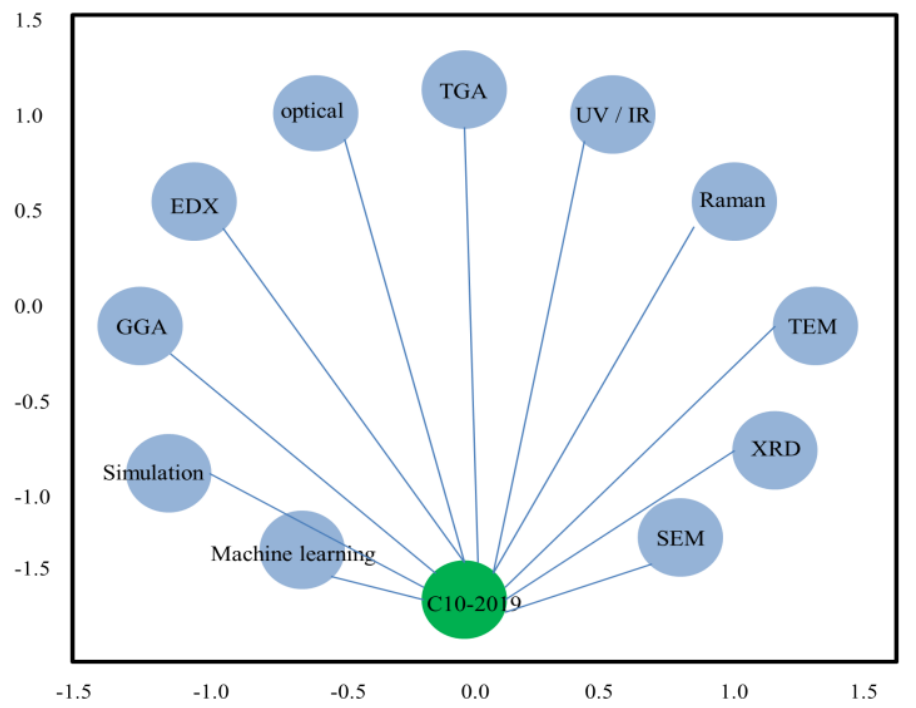

(b)

Fig. 4. Dataset Selected for the Classification from the Journal of Material Science (a) Materials (b) Methods. 
TABLE I. LIST OF SELECTED MATERIALS ALONG WITH INSTRUMENTAL METHODS USED FOR CHARACTERIZATIONS FROM THE JOURNAL PAPERS

\begin{tabular}{|c|c|c|}
\hline Sl no. & Material & Characterization techniques \\
\hline 1 & Graphene & $\begin{array}{l}\text { TEM, HRTEM, EELS, ITC, XPS, ES, Raman, } \\
\text { UV-Vis, DSC, TGA, Vickers hardness } \\
\text { indenter, Zeta potential, Material Studio (MD } \\
\text { simulation) }\end{array}$ \\
\hline 2 & $\mathrm{SiO}_{2}$ & $\begin{array}{l}\text { SEM, TEM, Raman, XRD, XPS, Raman, } \\
\text { Simulation }\end{array}$ \\
\hline 3 & $\mathrm{TiO}_{2}$ & TEM, SEM, TIFR, Raman, XRD, XPS \\
\hline 4 & YSZ & CALPHAD, TA, SEM, EDX, XRD, XPS, \\
\hline 5 & Carbon black & $\begin{array}{l}\text { XRD, SEM, TEM, Raman, IR camera, UV-Vis- } \\
\text { NIR }\end{array}$ \\
\hline 6 & Copper & $\begin{array}{l}\text { Raman, SEM, UV-Vis, FESEM, XRD, BET, } \\
\text { TEM, EIS, MD Algorithm }\end{array}$ \\
\hline 7 & $\begin{array}{l}\text { Organic } \\
\text { Polymer }\end{array}$ & $\begin{array}{l}\text { NMR spectra, FTIR, TGA, XPS, XRD, SEM, } \\
\text { BET, UV-Vis, Fluorescence spectra }\end{array}$ \\
\hline 8 & $\mathrm{SiC}$ & SEM, Raman, SRIM simulation \\
\hline 9 & Nanofibers & SEM, XRD, TEM, BET, TGA, Raman \\
\hline 10 & Ceramics & $\begin{array}{l}\text { Gibbs energy, DSC, TGA, XRD, SEM, } \\
\text { RADIANT }\end{array}$ \\
\hline
\end{tabular}

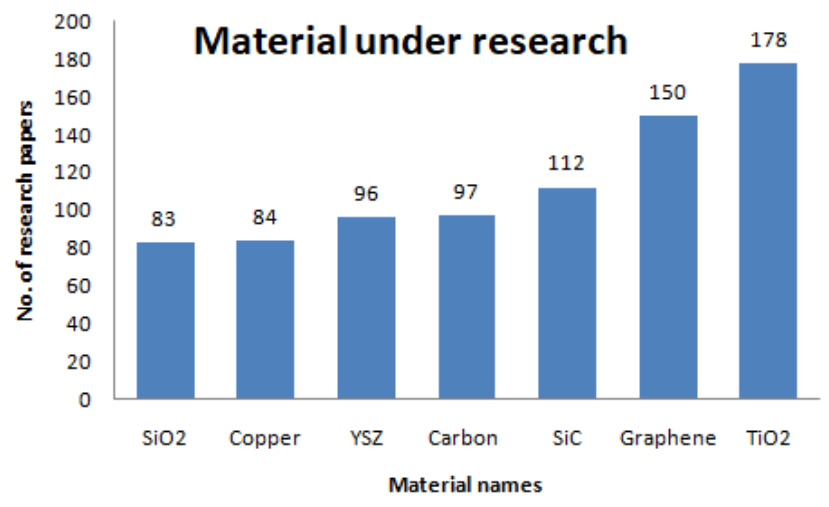

(a)

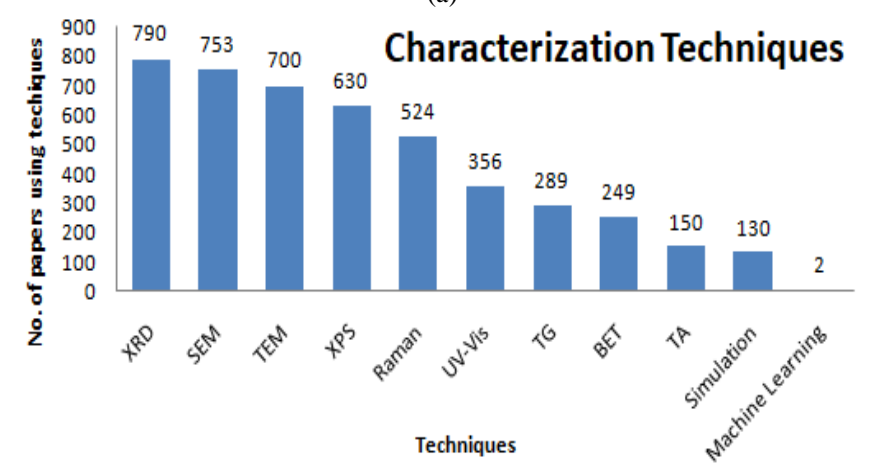

(b)

Fig. 5. Data Extracted from Journal of Material Science Papers (a) Top 7 Materials, (b) Top 10 Characterization Techniques.

The clustering is a frequency, which contains names, short names, and abbreviations using different alternatives for some well-known organization in acknowledgment section are added in the training dataset. Top 14 organizations which are acknowledged in Material Research Journal were analyzed for research publication. An analysis of the acknowledgment section along with organization and country names extracted from the Journal of Material Science for the past three years is shown in Fig. 6(a). Few selected funding agency are listed in Table II. According to the graph, NNSFC (National Natural Science Foundations of China) is the most acknowledged Chinese organization, involved in funding the most research projects. The analysis shows China published most research papers followed by the USA and other countries as shown in Fig. 6(b).

In summary, the results show that China published more research papers, and NNSFC funded the maximum project in past three years. The comparison shows the number of the research paper published by different countries in the past three years. This period can be extended to more number of years to validate our machine learning techniques. Once the author and organization parameters are extracted, built a social network of the acknowledgment section, and the snapshot of the social network is shown in Fig. 7.

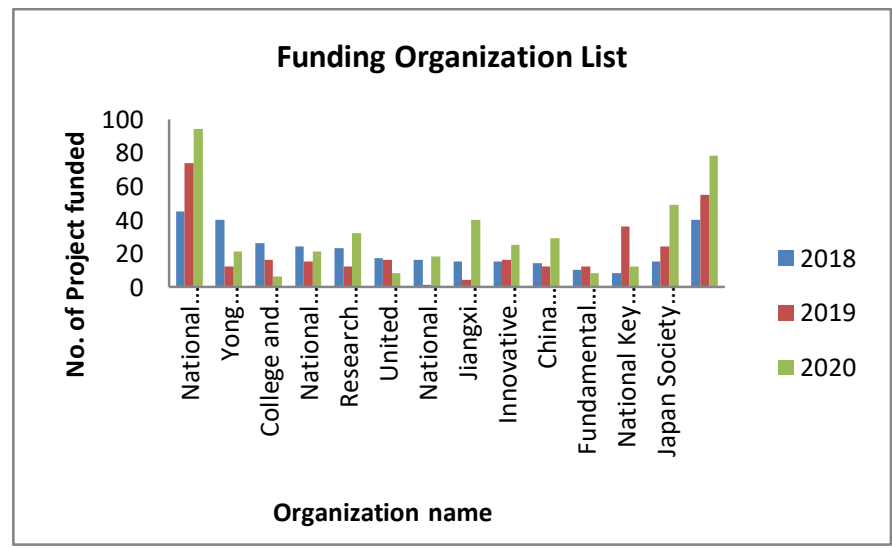

(a)

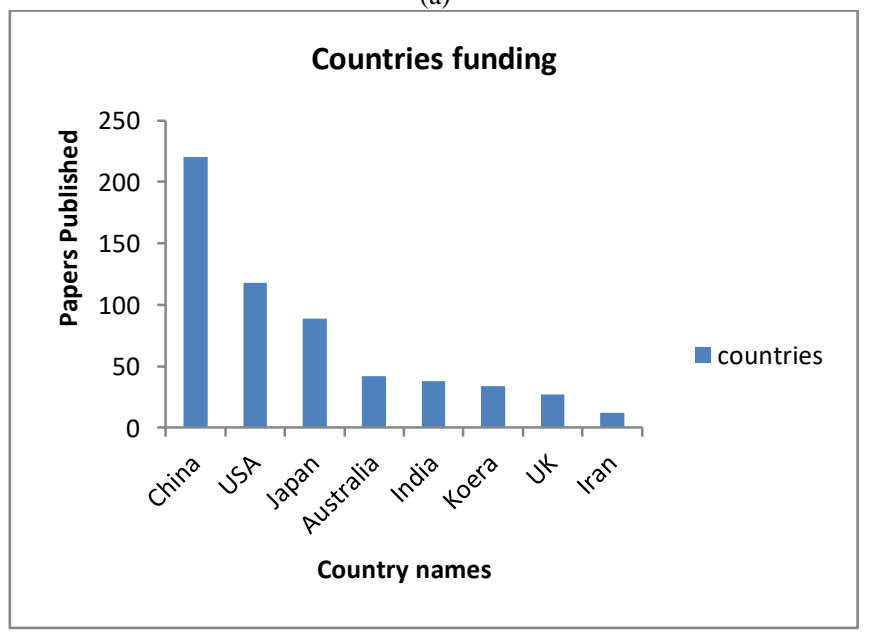

(b)

Fig. 6. Projects Funded from different Countries are Selected from Acknowledgment Section, (a) Bar Graph of different Organization Funded the Project from Past 3 Years Vs Number of Projects, (b) Bar Graph of Project Funding Countries Vs Number of Research Paper Published. 
TABLE II. LIST OF FUNDING AGENCY

\begin{tabular}{|l|l|}
\hline Sl no. & Funding agency \\
\hline 1 & National Natural Science Foundation \\
\hline 2 & Yong Teachers Scientific Research \\
\hline 3 & College and University Key Project \\
\hline 4 & National Funds for Distinguished Young Scientists \\
\hline 5 & Research Fund of University \\
\hline 6 & United Innovation \\
\hline 7 & National Research Agency \\
\hline 8 & Jiangxi Scientific / Education Fund \\
\hline 9 & Innovative Research Team in University \\
\hline 10 & China Scholarship Council \\
\hline 11 & Fundamental Research Funds for Central University \\
\hline 12 & National Key Research and Development Program \\
\hline 13 & Japan Society for the Promotion of Science \\
\hline 14 & National Science and Technology cooperation Funds \\
\hline
\end{tabular}

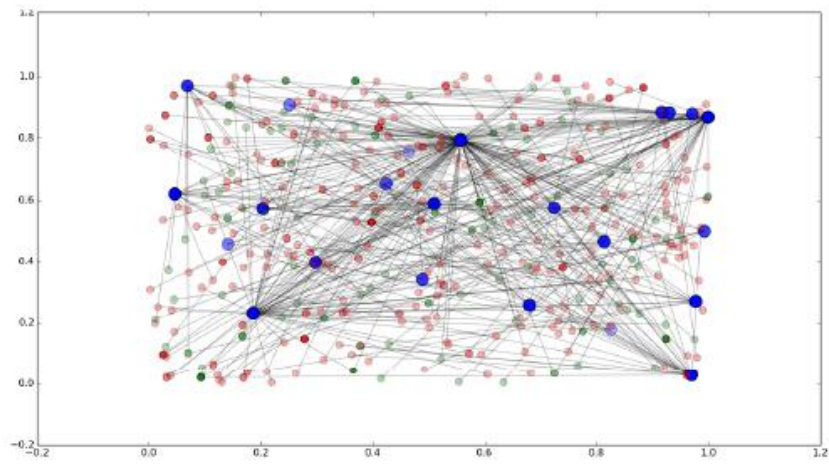

Fig. 7. Social Network of Acknowledgment Section Processed for 100 Published Research Papers. Blue $=$ Papers, Red $=$ Organization, Green $=$ Person.

Novelty and evaluation is a very important part of research work. Precision and recall are two extremely important model for evaluation metrics. While precision refers to the relevant percentage of results, recall refers to the percentage of total relevant results correctly classified by the algorithm. F-1 score is the harmonic mean of precision and recall. Both precision and recall are important to solve problems; one can select a model that maximizes the F1 score. To check the correctness of the predicted method terms, 20 research documents from the same journal were selected at random. Manually extracted methods and characterization techniques were used from the "Materials and Methods" sections and the results were compared with classification algorithms [21, 22]. Precision, Recall and F1-scores are different classification algorithms used to predict characterization techniques and organization names. Also we have computed dataset using LDA, NBS and LIBLINEAR to evaluate classification algorithms. LDA (Latent Dirichlet Allocation) is a generative probabilistic model for collections of discrete data such as text corpora [23]. NBC (Neighborhood Based Clustering) discovers clusters based on the neighborhood characteristics of data [24].
LIBLINEAR (Library for Large Linear Classification) uses logistic regression and linear support vector machines which is very efficient on large sparse datasets [25]. The values listed in Table III are the measured dataset from the classification algorithms; which concludes LDA, NBC and LIBLINEAR (SVM) and gives better F1 scores. Overall results show the novelty of our research work which generates and establishes tagged training dataset extracted from the materials and methods section using ML technique, which supports researchers to select advanced research topics.

TABLE III. EVALUATED DATASET MATRIX OF THE ClASSIFICATION ALGORITHMS

\begin{tabular}{|l|l|l|l|}
\hline Method list & Recall & Precision & F1-Score \\
\hline NBC & 0.68 & 0.32 & 0.41 \\
\hline LIBLINEAR & 0.68 & 0.30 & 0.41 \\
\hline Decision Tree & 0.83 & 0.24 & 0.37 \\
\hline MaxEnt & 0.72 & 0.26 & 0.38 \\
\hline Random & 0.48 & 0.16 & 0.24 \\
\hline LDA & $\mathbf{0 . 5 4}$ & $\mathbf{0 . 3 4}$ & $\mathbf{0 . 4 1}$ \\
\hline
\end{tabular}

\section{CONCLUSION}

Our analysis shows there are plenty of hidden information in each section of research journal papers. The extracted information can be used to extend the currently existing Citation Network. "Materials and Methods" and "Acknowledgments" are the least explored aspects of Scientometrics of Material Science Research papers. The methods and characterization from the "Materials and Methods" section, people and organizations acknowledged from the "Acknowledgments" section were extracted from "Journal of Material Science" and revealed important insight. A new researcher or a beginner can get an idea of material as well as the characterization methods used for completion of the research work. They can also understand which material, techniques are least explored for new research domains to proceed. Gives adequate information about the ongoing research problems, researchers are interested to find out the country, collaborators, and to propose new joint research project form different funding agencies. Future work involves extracting the "Abstract" and "Results" sections from scientific research journals. These two sections helps in summarizing the classification of completed research work, figures can be classified according to image quality and instrumental methods used for characterization of the materials. The complete dataset will help new researchers to select research work, find new domains and techniques to solve advanced scientific research problems.

\section{ACKNOWLEDGMENT}

This research did not receive any specific grant from funding agencies in the public, commercial, or non-profit sectors. I express my heartfelt gratitude to Prof. M Narasimha Murty and Mr. Rohit Kumar from Computer Science \& Automation department, IISc, Bangalore, India, for their constructive criticisms and timely directions which led to the successful completion of this work. 


\section{REFERENCES}

[1] Elliot J Yates and Louise C Dixon, "PageRank as a method to rank biomedical literature by importance", Source Code of Biology and Medicine, vol. 10, pp. 16-25, 2015.

[2] Jun Xu, Yaoyun Zhang, Yonghui Wu, Jinggi Wang M S, Xiao Dong M $\mathrm{D}$ and Hua $\mathrm{Xu}$, "Citation sentiment analysis in clinical trial papers", AMIA Annual Symposium Proceedings Archive, pp. 1334-1341, November 2015.

[3] Arthur Brack, Jennifer D Souza, Anett Hoppe, Soren Auer and Ralph Ewerth, "Domain-independent extraction of scientific concepts from research articles", Springer Nature Switzerland AG, pp. 251-266, 2020.

[4] C Lee Giles, Kurt D Ballacker and Steve Lawrence, "Citeseer: An automatic citation indexing system", Proceedings of the third ACM conference on Digital libraries, New York, pp. 89-98, 1998.

[5] Ionut Cristian Paraschiv, Mihai Dascalu, Stefan Trausan-Matu, Philippe Dessus, "Analyzing the semantic relatedness of paper abstract", $20^{\text {th }}$ International Conference on Control System and Science, pp. 759-764, 2015 [IEEE].

[6] Ramzan Talib, Muhammad Kashif Hanif, Shaeela Ayesha and Fakeeha Fatima, "Text mining: techniques, applications and issues", International Journal of Advanced Computer Science and Applications, Vol. 7, No. 11, pp. 414-418, 2016.

[7] M E J Newman, "Coauthorship networks and patterns of scientific collaboration, colloquium", The National Academy of Sciences of the USA, Vol. 101, pp. 5200-5205, 2004 [PNAS].

[8] Charles $H$ Davis and Blaise Cronin, "Brief communication acknowledgments and intellectual indebtedness: A bibliometric conjecture", Journal of the American Society for Information Science, vol. 44, no..10, pp. 590-592, 1993.

[9] Blaise Cronin, "Acknowlegdement trends in the research literature of informantion science", Journal of Documentation, 2001, Vol. 57, No. 3, pp. 427-433, 2001.

[10] B Akshaya, S S Sruthi Sri, A Niranjana Sathish, K Shobika, R Karthika and Latha Parameswaran, "Content-based image retrieval using hybrid feature extraction techniques", Springer Nature Switzerland AG, pp. 583-593, 2019 [ISMAC-CVB].

[11] Bin Umino, "Methods of automatic term recognition - A review", Proceedings of COLING, Mumbai, pp. 1211-1222, 2012 [Technical Papers].

[12] Madian Khabsa, Pucktada Treeratpituk, and C Lee Giles, "Ackseer: a repository and search engine for automatically extracted acknowledgements from digital libraries", Proceedings of the 12th
ACM/IEEE-CS joint conference on Digital Libraries, USA, pp. 185-194, 2012.

[13] Hospice Houngbo and Robert E Mercer, "Method mention extraction from scientific research papers", Proceedings of COLING, pp. 12111222, 2012.

[14] Bei Yu, "Automated Citation Sentiment Analysis: What can we learn from biomedical researchers", ASIS\&T Proceedings, vol. 50, no. 1, pp. 1-9, 2013.

[15] Xiaoyu Tang, Qingtian Zeng, Tingting Cui and Zeze Wu, "Regular expression-based reference metadata extraction from the Web", 2nd symposium on web society, pp. 346-350, 2010 [IEEE].

[16] Didier Bourigault, "Surface grammatical analysis for the extraction of terminological noun phrases", Proceedings of the COLING, pp. 977981, August 1992 [NANTES].

[17] David M W Powers, "Evaluation: From precision, recall and F-factor to ROC", Informedness, Markedness \& Correlation, Technical report SIE07-001, pp. 1-24, 2007.

[18] C Lee Giles and Isaac G Councill, "Who gets acknowledged: Measuring scientific contributions through automatic acknowledgement indexing", The National Academy of Sciences of the USA, vol.101, no. 51, pp. 17599-17604, 2004.

[19] Christopher D Mining, Mihai Surdeanu, Sohn Baner, Jenny Finkel, Steven J Bethard and David McClosky, "The Standford corenlp natural language processing toolkit", Proceedings of $52^{\text {nd }}$ annual Meeting of Association for Computational Linguistics, USA, pp. 55-60, June 2014.

[20] Kamal Sarkar, Mita Nasipuri and Suranjan Ghose, "Machine learning based keyphrase extraction: comparing decision trees, Navie Bayes and artifical neural networks", J Inf Process Syst, India, vol. 8, no. 4, pp. 693-712, December 2012.

[21] Kavitha Jayaram, Sangeeta , "A review: Information extraction techniques from research papers", ICIMIA, India, pp. 56-59, February 2017 [IEEE].

[22] David M Blei, Andrew Y Ng and Michael Jordan, "Latent dirichlet allocation", Journal of Machine Learning Research,vol. 3, pp. 993-1022, 2003.

[23] Rong-En Fan, Kai-Wei Chang, Cho-Jui Hsieh, Xiang-Rui Wang and Chih-Jen Lin, "LIBLINEAR: a library for large linear classfication", Journal of Machine Learning Research, 2008, 9: 1871-1874.

[24] Shuigeng Zhou, Yue Zhao, Jihong Guan and Joshua Huang, "A neighborhood-based clustering algorithm", Springer-Verlag Berlin Heidelberg, pp. 361-371, 2005 [LNAI 3518].

APPENDIX I. LIST OF EXTRACTED INFORMATION FROM SELECTED JOURNAL PAPERS

\begin{tabular}{|c|c|c|c|c|}
\hline Sl no & Paper title & Dataset & Extracted Content & Basis of Extraction \\
\hline 1 & $\begin{array}{l}\text { IE from Biomedical Literature: Methodology, } \\
\text { Evaluation and an Application (2003) }\end{array}$ & Biomedical dataset & $\begin{array}{l}\text { Biological terms in doc, } \\
\text { identify the common } \\
\text { concepts in group of genes }\end{array}$ & Dictionary, clustering of genes, \\
\hline 2 & $\begin{array}{l}\text { Automatic extraction of titles from general } \\
\text { documents using machine learning (ACM 2005) }\end{array}$ & $\begin{array}{l}\text { Internet of Microsoft, } \\
\text { DotGov, DotCom }\end{array}$ & Titles & $\begin{array}{l}\text { Improving of search ranking results } \\
\text { in doc retrieval by extracted titles }\end{array}$ \\
\hline 3 & $\begin{array}{l}\text { Mining knowledge from text using information } \\
\text { extraction (2005) }\end{array}$ & Book amazon.com & $\begin{array}{l}\text { Abstract knowledge, } \\
\text { concrete data }\end{array}$ & Knowledge, patterns \\
\hline 4 & Extracting procedures from text (2007) & Public recipe web site & Procedures and graphs & Building large knowledge \\
\hline 5 & $\begin{array}{l}\text { Automatic extraction and processing of document } \\
\text { references (2007) }\end{array}$ & CRF-based approach & $\begin{array}{l}\text { References, names of } \\
\text { related documents }\end{array}$ & $\begin{array}{l}\text { Search these doc in sys DB, create } \\
\text { links to respective documents }\end{array}$ \\
\hline 6 & $\begin{array}{l}\text { Opinion holder extraction from author and } \\
\text { authority viewpoints (2007) }\end{array}$ & MPQA corpus & Named entity extraction & $\begin{array}{l}\text { Opinion of author and authority } \\
\text { viewpoint }\end{array}$ \\
\hline 7 & $\begin{array}{l}\text { Entity categorization over large documents } \\
\text { collections (ACM KDD, 2008) }\end{array}$ & Web-data & $\begin{array}{l}\text { Entities ( people, movies, } \\
\text { painter, writer) }\end{array}$ & Categorizing extracted entities \\
\hline 8 & $\begin{array}{l}\text { Corpus study of kidney-related experimental data } \\
\text { in scientific papers (2009) }\end{array}$ & $\begin{array}{l}\text { Quantitative kidney } \\
\text { Database (QKDB) }\end{array}$ & Experimental data & $\begin{array}{l}\text { Automate extraction of experiment } \\
\text { and result section }\end{array}$ \\
\hline 9 & $\begin{array}{l}\text { Automatic creation of a technical trend map from } \\
\text { research papers and patents (ACM 2010) }\end{array}$ & $\begin{array}{l}\text { NTCIR-8 patent mining } \\
\text { task (Japanese data) }\end{array}$ & $\begin{array}{l}\text { Technology (algo, tools, } \\
\text { materials, data) }\end{array}$ & $\begin{array}{l}\text { Creating Technical trend map } \\
\text { (recall and precision) }\end{array}$ \\
\hline
\end{tabular}




\begin{tabular}{|c|c|c|c|c|}
\hline 10 & $\begin{array}{l}\text { Link Analysis in mind maps: a new approach to } \\
\text { determining doc relatedness (2010) }\end{array}$ & Maps & Reference & $\begin{array}{l}\text { Doc recommender if doc A and B } \\
\text { are refereed by mind map then } \\
\text { related }\end{array}$ \\
\hline 11 & $\begin{array}{l}\text { Contextual Information Extraction in Research } \\
\text { Articles: A case of developing contextual RDF } \\
\text { data for ESWC papers (ACM 2011) }\end{array}$ & $\begin{array}{l}\text { European Semantic Web } \\
\text { Conference (ESWC) }\end{array}$ & $\begin{array}{l}\text { Paragraphs containing } \\
\text { citations and classified } \\
\text { sentences }\end{array}$ & $\begin{array}{l}\text { Automatic context identification. } \\
\text { Author work, cited work used by } \\
\text { various authors, searching citation } \\
\text { sentences, export data in different } \\
\text { formats }\end{array}$ \\
\hline 12 & $\begin{array}{l}\text { Citation analysis and keyword mining based on } \\
\text { full text extraction of scientific literature (ACM } \\
\text { 2012) }\end{array}$ & ACM digital library & $\begin{array}{l}\text { Citation, bibliometric } \\
\text { analysis } \\
\text { (domain context graph) }\end{array}$ & $\begin{array}{l}\text { Domain knowledge graph and } \\
\text { analyzing interrelation of } \\
\text { publications for research direction }\end{array}$ \\
\hline 13 & $\begin{array}{l}\text { A comparison of metadata extraction techniques } \\
\text { for crowdsourced bibliographic metadata } \\
\text { management (2012) }\end{array}$ & e-prints, Mendeley dataset & Authors & $\begin{array}{l}\text { Conditional Random Fields and } \\
\text { SVM }\end{array}$ \\
\hline 14 & $\begin{array}{l}\text { Machine Learning based keyphrase extraction: } \\
\text { comparing decision trees, naïve bayes, and } \\
\text { artificial neural network (2012) }\end{array}$ & $\begin{array}{l}\text { Downloaded from } \\
\text { websites of journals } \\
\text { Springer, Elsevier, } \\
\text { (economics, law, medical) }\end{array}$ & $\begin{array}{l}\text { Comparing different } \\
\text { keyphrase extraction }\end{array}$ & Comparison of methods \\
\hline 15 & $\begin{array}{l}\text { ARTIC: metadata extraction from scientific papers } \\
\text { using a two-layer CRF model (2014) }\end{array}$ & $\begin{array}{l}100 \text { scientific papers from } \\
\text { IEEE, Elsevier, Springer } \\
\text { and ACM }\end{array}$ & $\begin{array}{l}\text { Title, author names, } \\
\text { emails, affiliations and } \\
\text { venue info }\end{array}$ & $\begin{array}{l}\text { Conditional Random Fields to } \\
\text { extract metadata from scientific } \\
\text { papers }\end{array}$ \\
\hline 16 & $\begin{array}{l}\text { Recommendation of newly published research } \\
\text { papers using belief propagation (2014) }\end{array}$ & DBLP dataset & Citation information & $\begin{array}{l}\text { Recommend most interesting newly } \\
\text { published paper }\end{array}$ \\
\hline 17 & $\begin{array}{l}\text { Scientific monitoring by mining scientific papers } \\
(2014)\end{array}$ & PDF and HTML & Semantic annotation & $\begin{array}{l}\text { Relation between organizations or } \\
\text { topics }\end{array}$ \\
\hline 18 & $\begin{array}{l}\text { Automatic extraction of main thesis documents } \\
\text { fields using decision trees ( } 2015 \text { International } \\
\text { conference on Computational Science and } \\
\text { Computational Intelligence) }\end{array}$ & $\begin{array}{l}\text { Downloaded thesis, } 65 \\
\text { documents (converted to } \\
\text { word format) }\end{array}$ & Title, abstract, authors & $\begin{array}{l}\text { Facilitate solving the research } \\
\text { problem process. Structuring thesis } \\
\text { document to help research to access } \\
\text { knowledge easily }\end{array}$ \\
\hline 19 & $\begin{array}{l}\text { Competing Algorithm Detection from Research } \\
\text { Papers (ACM 2016) }\end{array}$ & DBLP (small dataset) & $\begin{array}{l}\text { Algorithm names (name } \\
\text { entity extraction) }\end{array}$ & $\begin{array}{l}\text { Competing algorithm (ranking } \\
\text { based on number of comparisons }\end{array}$ \\
\hline 20 & $\begin{array}{l}\text { Insights from mining eleven years of scholarly } \\
\text { paper publications in requirements engineering } \\
\text { (RE) series of conferences (2016) }\end{array}$ & $\begin{array}{l}551 \text { papers from } \\
\text { Requirements } \\
\text { Engineering (RE) }\end{array}$ & $\begin{array}{l}\text { Topics frequently co- } \\
\text { occurring and connected } \\
\text { terms, co-author }\end{array}$ & $\begin{array}{l}\text { University-industry collaborations, } \\
\text { internal and external collaborations }\end{array}$ \\
\hline 21 & $\begin{array}{l}\text { PDFFigures 2.0: mining figures from research } \\
\text { papers (2016) } \\
\text { (more fig more citations) }\end{array}$ & $\begin{array}{l}\text { Introduce a new dataset of } \\
\text { comp science papers }\end{array}$ & $\begin{array}{l}\text { Figures and tables, } \\
\text { captions }\end{array}$ & $\begin{array}{l}\text { Component analysis, online search } \\
\text { engine, correlates figure citation. }\end{array}$ \\
\hline 22 & $\begin{array}{l}\text { Extracting code segments and their descriptions } \\
\text { from research articles ( } 2017 \mathrm{IEEE} / \mathrm{ACM} \\
\text { international conference on mining s/w } \\
\text { repositories (MSR) }\end{array}$ & IEEE digital libraries & Code example & Functionality and properties \\
\hline
\end{tabular}

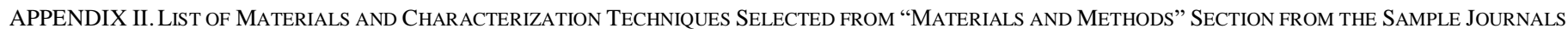

\begin{tabular}{|l|l|l|l|}
\hline Sl. No. & Title & Material & Characterization techniques \\
\hline 1 & $\begin{array}{l}\text { Evolution of phase during heating of metastable beta titanium alloy Ti- } \\
15 \mathrm{Mo}\end{array}$ & $\mathrm{Ti}$ & TEM \\
\hline 2 & $\begin{array}{l}\text { Mesoscale simulations of shock wave energy dissipation via chemical } \\
\text { reaction }\end{array}$ & Polymer & $\begin{array}{l}\text { MD Simulation (ChemDID), } \\
\text { shock tube }\end{array}$ \\
\hline 3 & $\begin{array}{l}\text { Oxygen ion mobility and conductivity prediction in cubic yttria-stabilized } \\
\text { zirconia single crystals }\end{array}$ & Yttria-stabilized zirconia (YSZ) & CALPHAD \\
\hline 4 & $\begin{array}{l}\text { Nitrogen-doped porous carbon derived from imidazole-functionalized } \\
\text { polyhedral oligomeric silsesquioxane }\end{array}$ & 3-Chioropropyltrimethoxysilane & $\begin{array}{l}\text { NMR, FTIR, TEM, SEM, XRD, } \\
\text { XPS and Raman spectrometer }\end{array}$ \\
\hline 5 & $\begin{array}{l}\text { Ultrahigh strength in nanocrystalline materials under shock loading } \\
\text { solid base catalyst for Knoevenagel condensations }\end{array}$ & Copper & Shockwave, simulation, TEM \\
\hline 6 & $\begin{array}{l}\text { Rational design of CuO nanostructures grown on carbon fiber fabrics with } \\
\text { enhanced electrochemical performance for flexible supercapacitor }\end{array}$ & CuO & XRD, SEM, TEM, XPS \\
\hline 7 & $\begin{array}{l}\text { Magnetoresistance of graphite intercalated with cobalt } \\
\text { g-C } \mathrm{N}_{4}\end{array}$ & FESEM, XRD, BET, EIS \\
\hline 8 & $\begin{array}{l}\text { Non-catalytic behavior of SiO }{ }_{2} \text { fine powders in presence of strong } \\
\text { shockwaves for aerospace application }\end{array}$ & SiO ${ }_{2}$ & $\begin{array}{l}\text { XRD } \\
\text { XRD, SEM, TEM, HRTEM, XPS }\end{array}$ \\
\hline 9
\end{tabular}




\begin{tabular}{|c|c|c|c|}
\hline 10 & $\begin{array}{l}\text { Thickness dependence of photoresponsive properties at } \mathrm{SrTiO}_{3} \text {-based } \\
\text { oxide heterointerfaces under different strains }\end{array}$ & $\mathrm{SrTiO}_{3}$-based oxide & $\begin{array}{l}\text { Atomic force microscopy (AFM), } \\
\text { X-ray reflectivity (XRR) }\end{array}$ \\
\hline 11 & Response of microstructure to annealing in-situ $\mathrm{Cu}-\mathrm{Nb}$ microcomposite & $\mathrm{Nb}$ with $\mathrm{Cu}-\mathrm{Nb}$ microcomposite & SEM, TEM \\
\hline 12 & $\begin{array}{l}\text { Poly ( } \varepsilon \text {-caprolactone)/cellulose nanocrystal nanocomposite mechanical } \\
\text { reinforcement and morphology: the role of nanocrystal pre-dispersion }\end{array}$ & Cellulose nanocrystal (CNC) & Young's modulus, TEM \\
\hline 13 & $\begin{array}{l}\text { Transparent heat insulation coatings with high selective shielding ability } \\
\text { designed with novel superstructures of copper sulfide nanoplates }\end{array}$ & $\mathrm{CuS}$ superstructures & $\begin{array}{l}\text { SEM, EDS, FESEM, XRD, FTIR, } \\
\text { UV-Vis }\end{array}$ \\
\hline 14 & $\begin{array}{l}\text { The effect of applied voltage on the corrosion resistance of } \mathrm{MgO}-\mathrm{C} \\
\text { refractories }\end{array}$ & $\mathrm{MgO}-\mathrm{C}$ & $\begin{array}{l}\text { Composition using EDS from } \\
\text { SEM facility }\end{array}$ \\
\hline 15 & $\begin{array}{l}\text { Experimental investigation on response and failure modes of 2D and 3D } \\
\text { woven composites under low velocity impact }\end{array}$ & Woven composites & $\begin{array}{l}\text { Olympus stereo microscope for } \\
\text { damage impact, C-scan }\end{array}$ \\
\hline 16 & $\begin{array}{l}\text { Aging response on the stress corrosion cracking behavior of wrought } \\
\text { precipitation-hardened magnesium alloy }\end{array}$ & Magnesium alloy & TEM \\
\hline 17 & $\begin{array}{l}\text { Flexible tuning of hole-based localized surface plasmon resonance in } \\
\text { roxbyite } \mathrm{Cu} 1.8 \mathrm{~S} \text { nanodisks via particle size, carrier density and plasmon } \\
\text { coupling }\end{array}$ & Nanocrystals (NCs) & TEM, SEM, UV-Vis, XRD \\
\hline 18 & $\begin{array}{l}\text { Ab-initio calculations of } \mathrm{CaZrO}_{3}(011) \text { surfaces: systematic trends in polar } \\
(011) \text { surface calculations of } \mathrm{ABO}_{3} \text { perovskites }\end{array}$ & Polar $\mathrm{CaZrO}_{3}$ & Ab-initio calculation (Simulation) \\
\hline 19 & $\begin{array}{l}\text { Tensile testing of aged flexible unidirectional composite laminates for } \\
\text { body armor }\end{array}$ & Composite laminates & SEM \\
\hline 20 & $\begin{array}{l}\text { On the binary Sb-Sn system: ab-initio calculation and thermodynamic } \\
\text { remodeling }\end{array}$ & Alloy of Sb-Sn & $\begin{array}{l}\text { Ab-initio calculation VESTA } \\
\text { software }\end{array}$ \\
\hline
\end{tabular}

APPENDIX III. LIST OF ABbreVIATIONS, Methods AND MEASUREMENT TECHNIQUES

\begin{tabular}{|c|c|c|c|}
\hline Sl. no. & Abbreviations & Methods & Measurements \\
\hline 1 & $\mathrm{AFM} / \mathrm{SFM}$ & $\begin{array}{l}\text { Atomic Force Microscopy / Scanning } \\
\text { Force Microscopy }\end{array}$ & $\begin{array}{l}\text { Very-high resolution type of scanning probe microscopy, force measurement, } \\
\text { topographic imaging and manipulation }\end{array}$ \\
\hline 2 & BET & Brunauer Emmett Teller & $\begin{array}{l}\text { The theory aims to explain the physical adsorption of gas molecules on a solid } \\
\text { surface and to measure porosity and surface specific area of nano materials. }\end{array}$ \\
\hline 3 & CALPHAD & Theoretical method & $\begin{array}{l}\text { A CALPHAD thermodynamic database allows the calculation of the equilibrium } \\
\text { state of "real" engineering materials. }\end{array}$ \\
\hline 4 & $\mathrm{CT}$ & Computed tomography & $\begin{array}{l}\text { It enables a three-dimensional representation of the internal and external structure } \\
\text { of objects with a detailed detect-ability which goes down into the micrometer } \\
\text { range. }\end{array}$ \\
\hline 5 & DTA & Differential thermal analysis & $\begin{array}{l}\text { The material under study in an inert atmosphere is made to undergo identical } \\
\text { thermal cycles while recording any temperature difference between sample and } \\
\text { reference. }\end{array}$ \\
\hline 6 & DFT (PBE-DFT) & $\begin{array}{l}\text { Density Function Theory (Perdew- } \\
\text { Burke-Ernzerh of DFT) }\end{array}$ & $\begin{array}{l}\text { Computational quantum mechanical modeling method used in physics, } \\
\text { chemistry, and materials science to investigate the electronic structure (or nuclear } \\
\text { structure) (principally the ground state) of many-body systems, in particular } \\
\text { atoms, molecules, and the condensed phases. }\end{array}$ \\
\hline 7 & EA & Electrochemical analyzer & $\begin{array}{l}\text { It provides trace metal analysis, trace organic analysis, computer-controlled } \\
\text { cyclic voltammeter, and chronoamperometry techniques. }\end{array}$ \\
\hline 8 & EDX or EDS & $\begin{array}{l}\text { Energy Dispersive X-Ray (EDX) } \\
\text { Energy Dispersive Spectroscopy (EDS) }\end{array}$ & $\begin{array}{l}\text { Chemical microanalysis technique used for elemental analysis in conjunction } \\
\text { with SEM. }\end{array}$ \\
\hline 9 & EELS & Electron Energy Loss Spectroscopy & $\begin{array}{l}\text { Material is exposed to a beam of electrons with a known kinetic energies. Some } \\
\text { of the electrons will undergo inelastic scattering, which means that they lose } \\
\text { energy and provides information on unoccupied energy level. }\end{array}$ \\
\hline 10 & EIS & $\begin{array}{l}\text { Electrochemical Impedance } \\
\text { Spectroscopy }\end{array}$ & $\begin{array}{l}\text { Study of doped spinal manganese cathode oxide materials synthesized for } \mathrm{Li} \text {-ion } \\
\text { batteries. }\end{array}$ \\
\hline 11 & $\begin{array}{l}\text { ELS Zeta } \\
\text { potentiometer }\end{array}$ & Electrophoretic Light Scattering & $\begin{array}{l}\text { In contrast, streaming potential measurements, no movement of the } \\
\text { liquid is generated, but the movement of the particles is used to measure } \\
\text { suspended particle size in fluids. }\end{array}$ \\
\hline 12 & $\mathrm{EPR} / \mathrm{ESR}$ & $\begin{array}{l}\text { Electron Paramagnetic Resonance / } \\
\text { Electron Spin Resonance }\end{array}$ & $\begin{array}{l}\text { Spectroscopic technique that detects species that have unpaired electrons, a } \\
\text { surprisingly large number of materials have unpaired electrons. }\end{array}$ \\
\hline 13 & ES / OES & $\begin{array}{l}\text { Emission Spectrometer / } \\
\text { Optical Emission Spectroscopy }\end{array}$ & $\begin{array}{l}\text { A rapid method for determining the elemental composition of a variety of metals } \\
\text { and alloys. Chemical analysis labs are equipped to evaluate the properties of } \\
\text { the material. }\end{array}$ \\
\hline
\end{tabular}




\begin{tabular}{|c|c|c|c|}
\hline 14 & FESEM / SEM & $\begin{array}{l}\text { Field Emission Scanning Electron } \\
\text { Microscope }\end{array}$ & $\begin{array}{l}\text { An advanced microscope offering increased magnification and the ability to } \\
\text { observe very fine features at a lower voltage than the SEM. }\end{array}$ \\
\hline 15 & FTIR & $\begin{array}{l}\text { Fourier Transform Infrared } \\
\text { Spectroscopy }\end{array}$ & $\begin{array}{l}\text { An analytical technique used to identify organic (and in some cases } \\
\text { inorganic) materials. The technique is used to obtain an infrared spectrum of } \\
\text { absorption and emission spectra of solid, liquid, and gas. }\end{array}$ \\
\hline 16 & Gibbs free energy & Calculated & Calculates the Thermodynamic potential of the material. \\
\hline 17 & HRTEM /TEM & $\begin{array}{l}\text { High Resolution Transmission Electron } \\
\text { Microscopy/ Transmission Electron } \\
\text { Microscopy }\end{array}$ & $\begin{array}{l}\text { High-resolution TEM offers resolution down to the Angstrom level and gives } \\
\text { information on the atomic packing, rather than just the morphology. Particle } \\
\text { growth can also be studied using TEM. }\end{array}$ \\
\hline 18 & Hybrid rheometer & & Accurate measure of frequencies, material types, and experimental designs. \\
\hline 19 & $\begin{array}{l}\text { Laser diffraction } \\
\text { particle size }\end{array}$ & & $\begin{array}{l}\text { Light scattering method for particle size analysis of covering a wide range from } \\
\text { submicron to millimeter scale. }\end{array}$ \\
\hline 20 & MST / ST & Material Shock Tube/Shock Tube & $\begin{array}{l}\text { It is a device consisting of driver and driven sections separated from a metal } \\
\text { diaphragm, used to accelerate the test gas in supersonic and hypersonic speed, } \\
\text { upon stopping it produces high temperature and pressure used to interact with } \\
\text { materials at the end of the shock tube }\end{array}$ \\
\hline 21 & NMR & $\begin{array}{l}\text { Nuclear magnetic resonance (NMR) } \\
\text { spectroscopy }\end{array}$ & $\begin{array}{l}\text { Used to determine the structure of organic molecules in solution and study } \\
\text { molecular physics, crystals as well as noncrystalline materials. Also used in } \\
\text { advanced medical imaging techniques, such as magnetic resonance imaging } \\
\text { (MRI). }\end{array}$ \\
\hline 22 & $\begin{array}{l}\text { Optical parameter } \\
\text { oscillator /OM }\end{array}$ & Optical microscope & $\begin{array}{l}\text { The basic optical microscope, improves resolution, uses visible light, easy to } \\
\text { develop. }\end{array}$ \\
\hline 23 & RADIANT & RADIANT ferroelectric testing & $\begin{array}{l}\text { Characterizing non-linear materials. Precision and accuracy have been the driving } \\
\text { force behind the engineering of test equipment and thin ferroelectric film } \\
\text { components. }\end{array}$ \\
\hline 24 & Raman Spectra & Raman Spectroscopy & $\begin{array}{l}\text { Commonly used in chemistry to provide a structural fingerprint by which } \\
\text { molecules can be identified. The technique typically used to } \\
\text { determine vibrational modes of molecules, although rotational and other low- } \\
\text { frequency modes of systems may also be observed. }\end{array}$ \\
\hline 25 & RT-MS & $\begin{array}{l}\text { Room Temperature-Monochromator } \\
\text { Spectrometer }\end{array}$ & $\begin{array}{l}\text { A monochromator produces a beam of light with a very narrow bandwidth of } \\
\text { light of single color. It is widely used for spectroscopic analysis of sample } \\
\text { materials. The incident light from the light source can be transmitted, absorbed, } \\
\text { or reflected through the sample. }\end{array}$ \\
\hline 26 & SPS & Syndiotactic Polystyren & $\begin{array}{l}\text { SPS techniques are refractory metals and intermetallics, oxide, and non-oxide } \\
\text { ceramics. The particles constituting the powders before consolidation tend to } \\
\text { decrease their surface energy by desorption of chemical species, once introduced } \\
\text { inside the SPS chamber. }\end{array}$ \\
\hline 27 & TCSPC & Time-correlated single-photon counting & $\begin{array}{l}\text { Fluorescence lifetimes, occurring as emissive decays from singlet-state, } \\
\text { approximated in time region from picoseconds to nanoseconds. }\end{array}$ \\
\hline 28 & TF Analyzer & Thin-film analyzer & $\begin{array}{l}\text { The most sophisticated analyzer of electro-ceramic materials and devices. The } \\
\text { test equipment is based on a modular idea, where four different probe heads can } \\
\text { be connected to the same basic unit. Each of the four-probe heads offers different } \\
\text { characterization methods. }\end{array}$ \\
\hline 29 & TG & Thermogravimetric Analysis & $\begin{array}{l}\text { Thermal analysis in which the mass of a sample is measured over time as the } \\
\text { temperature changes. }\end{array}$ \\
\hline 30 & USAXS & $\begin{array}{l}\text { Ultra-small-angle X-ray Scattering } \\
\text { Spectrometer }\end{array}$ & $\begin{array}{l}\text { SAXS and USAXS belong to a family of small angle X-ray scattering techniques } \\
\text { that are used in the characterization of materials. This instrument can record data } \\
\text { at smaller angle, to resolve and probe larger dimension objects. }\end{array}$ \\
\hline 31 & UV-Vis & Ultra Violet - Visible Spectroscopy & $\begin{array}{l}\text { It is absorption spectroscopy, measurement of attenuation of a beam of light after } \\
\text { it passes through a sample or after reflection from the sample surface. }\end{array}$ \\
\hline 32 & VSM & Value-Stream Mapping & Analyzes flow of materials. \\
\hline 33 & XPS / ESCA & $\begin{array}{l}\text { X-ray photoelectron spectroscopy or } \\
\text { Electron Spectroscopy for Chemical } \\
\text { Analysis }\end{array}$ & $\begin{array}{l}\text { Widely used for surface analysis technique because it can be applied to a broad } \\
\text { range of materials and provides valuable quantitative and chemical state } \\
\text { information from the surface of the material being studied. }\end{array}$ \\
\hline 34 & XRD & X-ray Powder Diffraction & $\begin{array}{l}\text { The analytical technique primarily to identify crystal structure, unit cell, particle } \\
\text { size and strain measurement. }\end{array}$ \\
\hline 35 & $\mathrm{XRF}$ & X-ray Fluorescence Spectrometer & $\begin{array}{l}\text { A non-destructive analytical technique used to determine the elemental } \\
\text { composition of materials. XRF analyzers determine the chemistry of a sample by } \\
\text { measuring the fluorescent (or secondary) X-ray emitted from a sample when it is } \\
\text { excited by a primary X-ray source. }\end{array}$ \\
\hline 36 & XRR & $\mathrm{X}$-ray reflectivity & $\begin{array}{l}\text { It is a analytical technique using reflected beam of x-rays from flat surface, } \\
\text { measured for the intensity of x-rays reflected in direction to understand surface- } \\
\text { sensitivities }\end{array}$ \\
\hline
\end{tabular}

